\title{
DISCURSO, HISTÓRIA E CORPO FEMININO EM ANTIGOS ANÚNCIOS PUBLICITÁRIOS
}

\section{Denise Gabriel WITZEL*}

- RESUMO: Situado nas fronteiras que a Análise do Discurso estabeleceu a partir do caminho proposto por Michel Foucault, o presente trabalho pretende mostrar como os discursos publicitários, que circularam no Brasil na primeira metade do século XX, contribuíram para a instauração de uma biopolítica das relações entre os sexos, mais precisamente para uma "sexualização" do gênero. A ideia foucaultiana de que o biopoder é o que pode se infligir tanto a um corpo que se pretende disciplinar como a uma população que se pretende regulamentar é a base sobre a qual examinamos o funcionamento discursivo da linguagem publicitária que, ao falar diretamente às mulheres, remete-nos a discursos outros que se cruzam pelos fios da memória, no interdiscurso, fixando as mulheres a seus corpos frágeis e à sua função materna, de acordo com os saberes, os poderes e as verdades que tradicionalmente regularam os ideais de feminilidade e permitiram a emergência de certos dizeres (e não outros).

- PALAVRAS-CHAVE: Discurso. Publicidade. Corpo feminino. Poder-saber.

\section{Introdução}

O corpo feminino concentrou, durante muito tempo, as marcas da inferioridade, da subordinação e da exclusão; foi alvo de inúmeras interpretações e representações; esteve sempre regulado por normas e valores de ordem moral, ética, estética e científica. Indagando sobre como antigos anúncios publicitários faziam circular na grande mídia esse corpo, mais precisamente os primeiros corpos femininos que irromperam na publicidade do início do século XX, proponho o presente trabalho com o objetivo de mostrar que os discursos sobre o corpo feminino, tomado como objeto de conhecimento e de saber, emergiram em uma rede tramada no/pelo poder-saber-verdade de que trata Michel Foucault e promoveram verdades sobre um corpo doente cujos resquícios ainda hoje estão enraizados em inúmeras práticas discursivas e no imaginário social.

Assim, a partir dos pressupostos da Análise do Discurso de linha francesa, em consonância com a arquegenealogia foucaultiana, pretendo discutir a constituição e a determinação histórica do sujeito em sua relação com as práticas discursivas

* Unicentro - Universidade Estadual do Centro-Oeste. Departamento de Letras. Guarapuava - PR - Brasil. 85070050 - denisewitzel@uol.com.br 
que forjaram, no espaço midiático, a identidade do sujeito-mulher-frágil. A análise de antigas propagandas de medicamentos dará visibilidade ao trabalho da linguagem publicitária atravessada, dentre outros, pelo discurso médico, cujos efeitos de sentido implicam a promessa de cura e reverberam imagens coletivas construídas em séries enunciativas que firmaram regiões de sentidos e contribuíram para o delineamento de identidades do homem e da mulher de outrora, instigando-nos a verificar o que permanece e o que desaparece desse passado nos jogos de verdade que subjetivam ambos na contemporaneidade.

Para refletir sobre o funcionamento discursivo de lugares e papéis sociais historicamente construídos, que produzem efeitos de verdade, iniciaremos tratando sumariamente das noções foucaultianas de poder e de biopoder; na sequência, discutiremos questões referentes à constituição do corpo da mulher para, então, analisar o corpo narrativizado nos anúncios publicitários, concebido como portador e, ao mesmo tempo, produtor de sentidos.

Nosso corpus de análise foi constituído a partir de uma seleção de anúncios publicados em um livro intitulado Reclames da Bayer, organizado por essa empresa, em 1986, em comemoração aos seus 90 anos de atividades no Brasil. Esses anúncios foram veiculados nos principais jornais e revistas do Rio de Janeiro e de São Paulo, entre 1911 e 1942, e documentaram, de forma valiosa, os costumes, os modos de vida, os ideais de comportamento, enfim, os modos de subjetivação do feminino (e do masculino) em um contexto sócio-histórico que inaugurou a sociedade capitalista tal qual a conhecemos hoje. Esse retorno ao passado e à memória tem como alvo a compreensão do presente, pois é investigando o campo dos enunciados que se torna possível entender os acontecimentos discursivos que possibilitaram a emergência de outros enunciados e a produção de "novos" sentidos.

Nessa linha de raciocínio, entendemos, na esteira de Foucault (2007, p.137), o discurso como:

[...] um bem - finito, limitado, desejável, útil - que tem suas regras de aparecimento e também suas condições de apropriação e de utilização; um bem que coloca, por conseguinte, desde sua existência (e não simplesmente em suas 'aplicações práticas') a questão do poder; um bem que é, por natureza, o objeto de uma luta, e de uma luta política.

\section{Do poder disciplinar ao biopoder}

Pensando especificamente no poder e nos discursos por ele produzidos e reproduzidos, é importante sublinhar que, segundo Foucault (1988, p. 102), "o poder está em toda parte", circula em todas as instâncias, recobre as instituições e os indivíduos, reproduz-se a cada instante, atinge todos os domínios da vida 
humana. Está pulverizado na sociedade, atuando em pequenos enfrentamentos, nas microlutas diárias, e seus efeitos atingem "[...] a realidade mais concreta dos indivíduos - o seu corpo, e que se situa ao nível do próprio corpo social, e não acima dele, penetrando na vida cotidiana e por isso podendo ser caracterizado como micro-poder ou subpoder." (MACHADO, 2006, p. 168).

Não se possui poder; exerce-se poder, ou seja, por não ser uma propriedade ou uma coisa, ninguém o detém, não é algo que se possa tomar ou dar, ganhar ou perder. Não está localizado em nenhum lugar específico e atinge a todos, passando por entre todos, para uni-los e separá-los ao mesmo tempo, para reunilos no próprio conflito que os cliva; somente é percebido como um conjunto de relações de força, funcionando em acontecimentos singulares (entre um homem e uma mulher, entre aquele que sabe e aquele que não sabe, entre os pais e as crianças, na família etc.), nos movimentos históricos e na própria história. Nesses campos de correlações de forças, ele não é transcendente, mas imanente a outros tipos de relação (cognitivas, econômicas, sexuais). Coexiste necessariamente com pontos de resistências que funcionam como adversidades, alvo, apoio e saliência. São pontos presentes em toda rede de poder, por isso Foucault não aceita a ideia de que há um único lugar de recusa, "alma da revolta, foco de todas as rebeliões, lei pura do revolucionário” (FOUCAULT, 1988, p. 106). O que há são resistências, no plural.

Rejeita igualmente a noção de repressão, na medida em que, ao se definirem os efeitos do poder pela repressão, ele é identificado como uma força da proibição, uma lei que diz "não". "O que faz com que o poder se mantenha e que seja aceito é simplesmente que ele não pesa só como uma força que diz não, mas que de fato permeia, produz coisas, induz ao prazer, forma saber, produz discurso [...]" (FOUCAULT, 1979, p. 8). Trata-se, com efeito, de uma eficiente rede produtiva de sujeitos e discursos mais do que uma instância negativa que tem por função reprimir.

A problemática do poder adquire, na obra de Foucault, pelo menos três modos de funcionamento não excludentes, ou seja, modos interrelacionados. São eles: o poder soberano, o poder disciplinar e o biopoder. Mais especificamente sobre os dois últimos, importa dizer que o poder disciplinar, tema central de Vigiar e Punir, surge ao longo dos séculos XVII e XVIII, quando a sociedade altera seu modo de entender os comportamentos desviantes diante da norma. Se, antes, os crimes eram uma afronta ao poder soberano, que possuía direito de vida e morte sobre os indivíduos, e o criminoso deveria se submeter aos rituais públicos do suplício, de forma a fazer ver e temer a força do Monarca; agora, o castigo passa a simbolizar o desrespeito ao corpo social e a ser um procedimento com o objetivo de reparar a perturbação causada à sociedade. O suplício cede lugar ao enclausuramento. 
Concentra-se, o poder disciplinar, no corpo "[...] como máquina: no seu adestramento, na ampliação de suas aptidões, na extorsão de suas forças, no crescimento paralelo de sua utilidade e docilidade, na sua integração em sistemas de controle eficazes e econômicos." (FOUCAULT, 1988, p. 151); surgem, em decorrência, verdadeiras instituições disciplinares (fábricas, hospitais, escolas, prisões etc.) que se multiplicam e estendem seus tentáculos até atingirem todo o corpo social. Esse mecanismo de poder se materializa nos corpos dos sujeitos individualizados, mediante técnicas de controle asseguradas por procedimentos que caracterizam as "disciplinas: anátomo-política do corpo humano". São técnicas que desencadeiam ações específicas sobre o corpo, como as que visam adestrar os gestos, regular os comportamentos, normalizar o prazer, "com o objetivo de separar, comparar, distribuir, avaliar, hierarquizar", fazendo com que surja "[...] pela primeira vez na história esta figura singular, individualizada - o homem - como produção do poder." (MACHADO, 1979, p. 20). Produto, pois, de um intricado processo de objetivação que se dá no interior das tramas do poder, mas também, e ao mesmo tempo, objeto de saber.

Tal produção de corpos vai ao encontro da fabricação do homem necessário ao funcionamento e manutenção da sociedade industrial capitalista. Isso significa, em outras palavras, que a disciplina é uma tecnologia específica do poder que age na constituição de indivíduos dóceis e úteis, aptos ao trabalho fabril. Para garantir tal efeito, são desenvolvidos eficientes mecanismos de punição incessante e de vigilância ininterrupta, a exemplo da invenção do panóptico, em 1785, pelo filósofo Jeremy Bentham: prisão modelo com uma composição arquitetônica de caráter coercitivo e disciplinatório, cuja disposição faz com que haja um controle intenso e constante de todos os atos dos indivíduos. Sua eficácia resulta da divisão entre o ver e o ser visto. O poder desaparece, ele não mais se representa, mas existe.

Com esse mecanismo, o poder se converteu em algo ubíquo, onipresente, mas invisível, inverificável e fez derivar um funcionamento automático muito eficiente, pois, ao saberem-se sujeitos à vigilância, mesmo que não se confirme a presença do vigia, os indivíduos disciplinam-se a si mesmos e o fazem constantemente. Por isso, a interiorização do olhar do outro produz um efeito de subjetividade: a culpa, o autocontrole, o cumprimento de normas e a disciplina constante são alguns dos modos pelos quais os sujeitos são constituídos a partir da obrigação de vigiar a si mesmos. Pode-se igualmente dizer que o dispositivo do poder disciplinar compreende saberes e instituições, o que fez surgir uma tecnologia renovada do poder, mais complexa e mais abrangente, na medida em que o panóptico se transformou em panoptismo.

Com relação ao biopoder, em a Vontade de saber (História da Sexualidade I), Foucault postula que ele surgiu de modo complementar ao poder disciplinar. 
Este último se transformou, no século XVIII, porque passou a integrar outras e novas técnicas que se deslocaram do corpo-indivíduo para o corpo-espécie, "[...] o corpo transpassado pela mecânica do ser vivo e como suporte dos processos biológicos: a proliferação, os nascimentos e a mortalidade, o nível de saúde, a duração da vida, a longevidade, com todas as condições que podem fazê-las variar." (FOUCAULT, 1988, p. 152). É um poder que age de forma positiva, na medida em que age como um desencadeador de forças que não mais se exercem sobre a morte, mas sobre a vida. Em outros termos, os efeitos do biopoder se fazem sentir, na contemporaneidade, nas intervenções e nos controles reguladores da população. Aplicam-se não mais nos corpos dos indivíduos, mas na gestão de suas vidas. Trata-se, em consequência, de uma biopolítica que representa uma "grande medicina social" (REVEL, 2005, p. 27).

Para exemplificar os efeitos do biopoder, Foucault mostra que as regras que se impuseram no curso do século XVIII centravam-se nos modos de vida social e traçavam as diretrizes de vida para a população. Os discursos produzidos nesse momento voltavam-se para as políticas das cidades e de suas populações e os problemas passaram a ser vistos de forma coletiva e não mais isolada ou individualizada. Onde morar, o que é higiene, como fazer sexo, em que medida controlar ou não a natalidade, quais seriam as horas de prazer e de dor de uma sociedade toda, como fazer para ampliar ou não a longevidade, o que fazer para ter uma administração do "bem-estar social" são alguns dos enfoques valorizados nessa prática do biopoder que se aplica tanto a um corpo que se quer disciplinar quanto a uma população que se quer regulamentar.

Nesse contexto, a mulher, ou melhor, seu corpo, sua vida e, principalmente, seu sexo passaram a ser alvo dos efeitos normalizadores do biopoder, pois a ela cabia a responsabilidade de cuidar da saúde de seus filhos, garantindo-lhes a longevidade, além de manter a solidez da instituição familiar, assegurando certa ordem social. Uma medicalização minuciosa focalizava especialmente a questão da histerização e, ao medicá-la, instaurou-se um intenso controle sobre seus excessos, suas condutas, sua direção espiritual e seus modelos de vida.

Em suma, os efeitos do poder disciplinar e os do biopoder se concretizam de forma mais evidente e intensa no corpo. E para mostrar que o corpo das mulheres figura no centro de "maneira imediata e específica" (PERROT, 2005, p. 447), vale descrever e analisar esse corpo focalizando sua história, o modo como ele foi vivenciado e expresso no interior de sistemas culturais particulares. Parto do princípio de que o corpo feminino foi erigido como um objeto misterioso e frágil e que o poder não pesou sobre esse corpo somente como uma força repressora. Na longa duração da história das mulheres, ele, o poder, agiu como uma eficiente força produtora de enunciados desencadeadores de práticas e subjetividades. 


\section{Breve história do corpo feminino}

"Durante muito tempo se tentou fixar as mulheres à sua sexualidade. 'Vocês são apenas o seu sexo, dizia-se a elas [...]. E este sexo, acrescentaram os médicos, é frágil, quase sempre doente e sempre indutor de doenças. 'Vocês são a doença do homem"'. Inicio com essas palavras de Foucault (1979, p. 234), extraídas de Não ao sexo rei, para situar este estudo relativamente à história do corpo da mulher, que é, igualmente, a história de uma dominação estribada em relações de poder, em vontade de saber e em discursos verdadeiros. Que corpo é este que se constituiu de forma marcada no sexo frágil, determinando-lhe lugares, interditos, liberdades, trabalhos, limites e exclusões?

Entretanto, antes de iniciar quaisquer observações a respeito do corpo feminino, é necessário esclarecer que o corpo em questão não é, obviamente, o corpo objetivo, material e mortal, resultado de uma somatória de átomos e moléculas que desempenham funções fisiológicas e biológicas, tampouco o corpo inerte com suas propriedades eternas. Mas o corpo imerso na história, fabricado discursivamente; logo, o corpo como irrupção de um acontecimento. Trata-se de uma construção simbólica inscrita em redes de poder e resistências. Possui uma história física, estética, política, ideal e material, que se transforma nos tempos e nos espaços.

Uma vez produto da historicidade, a problemática do corpo feminino desde sempre provocou diferentes e, muitas vezes, divergentes posicionamentos. Foi objetivado e manipulado pelo poder médico; censurado, confiscado e fortemente vigiado pelo poder religioso; foi, ao longo da grande duração de sua história, tratado como território de posse e de cultivo masculino, "vaso receptor", ora sagrado ora laico, conforme destacam Matos e Soihet (2003). Ainda que exaltado, admirado e exposto por grandes nomes da literatura e das artes em geral, o que prevalece como marca identitária desse corpo, que às vezes padece e às vezes reina, são seus mistérios, suas forças inequívocas, seus perigos e seus interditos.

Nos estudos sobre os silêncios da história das mulheres, desenvolvidos pela historiadora francesa Michel Perrot $(2003,2005)$, destacam-se os rastros que fundamentaram as raízes do silêncio acerca do corpo da mulher. Para dar visibilidade ao fato de que esse corpo se inscreve na construção do pensamento simbólico da diferença entre os sexos, reforçado ao longo do tempo pelo discurso médico ou político, a historiadora, dentre muitos outros pontos, dá relevo a dois efeitos de um poder-saber normatizador e, consequentemente, a dois efeitos da vontade de verdades que ainda hoje pesam sobre o ser mulher.

O primeiro refere-se às interpretações dos estudos filosóficos da Grécia antiga, os quais associavam o corpo da mulher a 
[...] uma terra fria, seca, a uma zona passiva, que se submete, reproduz, mas não cria; que não produz nem acontecimento nem história e do qual, consequentemente, nada há a dizer. O princípio da vida, da ação, é o corpo masculino, o falo, o esperma que gera, o pneuma, o sopro criador. Cavernoso, oculto, matricial, o útero se subtrai. É um abismo sem fundo no qual o homem se esgota, deixa sua força e sua vida. Entre os medos que o homem tem da mulher e que lhe alimentam a ginecofobia, figura o do insaciável desejo feminino que o conduz à impotência. (PERROT, 2003, p. 20-21).

A elaboração desses saberes, fundamentados nas diferenças entre os sexos, converteu-se em sólidos argumentos para justificar a imperfeição e a inferioridade das mulheres. Elas, por serem consideradas seres frios e mais fracos, eram essencialmente equipadas para a "[...] geração e criação dos filhos, não para uma vida racional e ativa dentro do fórum cívico. As mulheres eram criaturas privadas, os homens eram públicos [...]" (PORTER, 1992, p. 316). Paralelamente à verdade sobre a inferioridade anatômica e biológica, destacase a verdade da necessidade de ela ficar confinada à esfera doméstica, lócus de proteção, sujeita "[...] às gestações sem fim, aos cuidados das crianças, ao envelhecimento prematuro, à exaustão e, frequentemente, à morte por doenças do parto." (PORTER, 1992, p. 316).

$\mathrm{Na}$ (des)continuidade histórica, muitas propostas disciplinarizadoras dos corpos femininos assentavam-se no discurso fundante da inferioridade. Dentre as principais, merecem destaque as práticas discursivas e não discursivas das grandes religiões monoteístas ocidentais. Eis, pois, o segundo ponto assinalado por Perrot (2003), que muito contribuiu para o delineamento do estigma da fragilidade feminina.

O Gênesis relata o drama vivido pelo primeiro casal, responsabilizando a mulher por toda dor e sofrimento da humanidade. Desde então, ecoam em não poucos discursos, de diferentes ordens, os sentidos que associa(ra)m o corpo da mulher ao pecado, objetivando-o como tentador, força do mal, do qual é urgente se defender. Daí ser necessário, segundo Perrot (2003), reduzi-la ao silêncio, impor-lhe o silêncio. Resquícios dessa interpretação fizeram com que religiosos e seus seguidores rejeitassem a sexualidade e considerassem o corpo da mulher como impuro e corruptor; " [...] só a procriação justifica a cópula, sendo a castidade superior ao matrimônio, mesmo o cristão: velando-a [...]" (PERROT, 2003, p. 23). A propósito dessa prática de "velar" as mulheres, lembremo-nos de que às mulheres religiosas, consagradas à virgindade, foi imposto o uso do véu, seguidas por todas aquelas que precisaram dar a ver a marca do pudor.

Se hoje o islã é o seu principal defensor, o véu tem uma história mais longa e um significado muito mais vasto: é o instrumento e o símbolo da invisibilidade e do silêncio impostos às mulheres em virtude do perigo 
que se crê que elas representam. O véu exprime, pois, o medo que os homens têm das mulheres e sua vontade de se apropriar de seus corpos. (PERROT, 2003, p. 23).

Enredado nessas tramas de saber-poder, o corpo em geral, o corpo da mulher em particular, passa, no século XVIII, a ser de especial interesse do discurso e da ação médica. Houve uma significativa reinterpretação desse corpo à luz das novas verdades descobertas pela medicina e pela biologia. Não era mais somente em relação ao sexo que havia diferenças entre homem e mulher, mas em todos os domínios do corpo e da alma, em cada aspecto moral e físico. Também nesse momento histórico, descobriu-se a função dos ovários e a natureza do ciclo menstrual e, consequentemente, descobriu-se que não havia razão para as mulheres serem consideradas um ser sexualmente ativo. Por isso, existem as tradicionais convicções de que não seria necessário nenhum estímulo para as mulheres conceberem, o que fortaleceu a premissa de que elas deveriam servir apenas de receptáculos. No desdobramento dessas interpretações, que dessexualizaram as mulheres, irrompeu um maior controle sobre elas, sobretudo porque passaram a ser associadas à figura sacralizada da mãe, espelhando a santa e virgem Maria.

Assim, o poder médico, legitimado para produzir efeitos de verdade, impôs novas delimitações e determinações normativas; sedimentou a definição dos papéis sociais e sexuais para os homens e as mulheres; delineou cientificamente as marcas da fragilidade e da consequente necessidade de cuidados e de proteção. A medicina, ao comprovar que as tradicionais funções de ambos os sexos estavam legitimamente vinculadas aos aspectos anatômicos e biológicos, estabilizou as certezas de que as mulheres eram seres mais fracos, débeis, limitados às condições de um corpo que sangra e que engravida. Os efeitos disso tudo, ainda hoje, normatizam, julgam, discriminam, orientam, classificam, obrigam, coagem... trazendo sempre consigo efeitos específicos de poder médico masculino.

Para mostrar particularmente como o discurso médico arregimentava uma série complexa de marcas identitárias, impingindo modos de ser mulher em um tempo não tão distante, voltar-me-ei, na sequência, analiticamente para peças publicitárias que têm como foco a venda de medicamentos ora para combater os males femininos; ora, os males masculinos. Meu intuito é pensar no funcionamento do discurso publicitário como espaço de reverberação dos discursos médicos que consolidaram algumas diferenças tão caras no delineamento dos corpos femininos.

\section{Corpos femininos em antigos anúncios publicitários}

Uma das características mais marcantes dos anúncios publicitários, de uma forma geral, é que, embora os significados produzidos sejam públicos, 
compartilhados, coletivos, o desejo de compra é despertado se, paradoxalmente, os anúncios atingirem a individualidade, ou seja, a compra deve ser percebida pelo consumidor como um ato de escolha, exercício da vontade e do livre controle. Ademais, para que a estratégia de persuasão de um anúncio funcione, é imprescindível que o leitor-consumidor reconheça e aceite as imagens sociais de seu próprio corpo, ali discursivizado de modo a lembrar seu corpo real. Apresentado como realidade, o corpo produz efeitos de sentido que regulamentam de forma poderosa os comportamentos sociais por meio de um "[...] agenciamento coletivo de enunciação, entrecruzando determinações coletivas sociais, econômicas, tecnológicas etc." (GREGOLIN, 2007, p. 21).

A produção discursiva abaixo, por exemplo, ao falar diretamente à figura feminina, enfatiza como as mulheres eram; enuncia as verdades sobre seu corpo; reitera crenças amplamente difundidas no imaginário social; (re)afirmam, sobretudo, os saberes científicos da época que definiram a mulher como um ser doente. E é com essa imagem coletiva que nossas ancestrais, em sua existência particular, deveriam se identificar.

Figura 1 - PP de jan. 1921

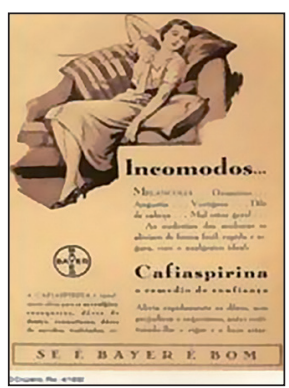

Fonte: BAYER (1986).
Incomodos...

Melancolia... Desanimo... Angustia.... Vertigem... Dôr de cabeça... Mal estar Geral !...

As moléstias das senhoras se aliviam de forma fácil, [...]
Figura 2 - PP de jan. de 1921

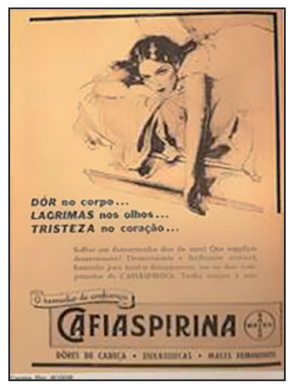

Dôr no corpo... LAGRIMAS nos olhos... TRISTEZA no coração... Soffrer em determinados dias do mês! Que supplicio desnecessário! [...] MALES FEMININOS

Fonte: BAYER (1986).

Mulheres prostradas, com visível abatimento físico, inertes em uma poltrona ou debruçadas sobre uma cama; formulações linguísticas que as descrevem como um ser atravessado pelo sofrimento, extremamente carente de cuidados. Eram essas as posições de sujeito mais reiteradas nos anúncios de medicamentos que circularam na mídia impressa há cerca de cem anos. No contraste dessas figuras debilitadas, emerge ora a figura vigorosa, forte e valente do homem, enfrentando, por exemplo, um touro com o tórax (figura 3); ora a figura de um homem com aparência cansada, simulando uma dor de cabeça ou mal-estar, nitidamente em decorrência de um desgaste mental (figura 4). Este nunca está deitado, exaurido ou prostrado; na maioria das vezes é representado com uma das mãos na testa. 
Figura 3 - PP de nov. 1914

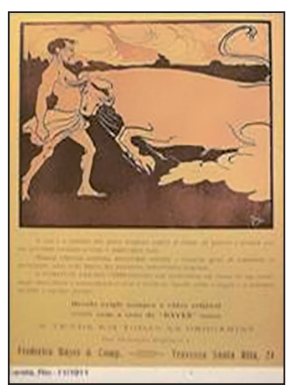

Fonte: BAYER (1986).
A vida e o trabalho nos paizes tropicaes esgota as forças do homem e termina com sua actividade tornando-o triste e inapto para tudo. Anemia, chlorose, cachexia, nervosidade extrema e fraque-

za geral do organis-

mo se apresentam, sobre tudo depois das innumeras enfermidades tropicaes. [...]

\section{Figura 4 - PP de nov. 1914}

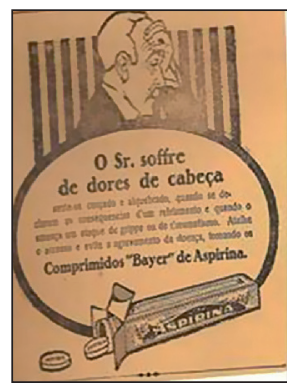

Fonte: BAYER (1986).
O Sr soffre de dores de cabeça

Sente-se cançado e alquebrado, quando se declaram as consequências d'um refriamento e quando o ameaça um ataque de grippe ou de rheumatismo.[...]

"Por que esses e não outros enunciados?" perguntaria Foucault (2007, p.26). Todo acontecimento discursivo é uma irrupção de uma singularidade, configurando-se como "nó de uma rede", ligado a outros acontecimentos emaranhados numa dispersão temporal e apreendidos numa pontualidade. Os outros acontecimentos, portanto, compõem os saberes que deram sustentação às verdades fundantes dos discursos das peças em questão. Foram produzidas quando o corpo feminino, de um lado, foi interpretado como corpo subordinado e, de outro, normatizado biologicamente com base no modelo masculino. Os efeitos dessas interpretações produziram os corpos reatualizados na materialidade das peças acima; corpos saturados de fragilidade em oposição aos saturados de virilidade.

Nas peças, observam-se os reflexos das práticas que outrora inscreveram o corpo nos sistemas de regulação/coerção que desconhecemos, mas cujos efeitos sedimentaram modos de ser e de estar no mundo do homem e da mulher constantemente rememorados em formulações enunciativas que insistem nessas marcas de feminilidade e de masculinidade, apesar das muitas outras verdades que surgiram, principalmente a partir da segunda metade do século XX, com os avanços dos feminismos.

Corroborando, reafirmando e reproduzindo as verdades que prenderam a mulher à fraqueza de seu corpo, as peças falam de um ser reduzido a seus órgãos internos e inferiores (seu centro vital), ao contrário do homem, que tem na cabeça e nas regiões superiores do corpo, sua força e seu poder. A publicidade antiga acolhe e reverbera os discursos forjados na rede de poder que produziu as 
identificações do ser mulher, fixando regiões de sentidos em torno da condição patológica do corpo feminino. Ao enunciar, por exemplo, incômodo, as moléstias das senhoras (figura 1) e os males femininos (figura 2) como causadoras de melancolia, angústia, desânimo, vertigem, dor de cabeça e mal-estar geral (figura 1), além de dor no corpo, lágrimas nos olhos e tristeza no coração (figura 2), a publicidade não deixa nenhuma dúvida sobre a fabricação do corpo doente feminino.

São esses e outros dizeres, inscritos na mesma formação discursiva, que outrora se fundamentaram na anatomia e na fisiologia, adquirindo força e extensão inalcançáveis, com importantes desdobramentos morais, políticos e, seguramente, identitários para as mulheres. Em suas diferentes materialidades, as peças em questão (re)afirmam: a mulher é um sexo frágil, ao que fazem eco discursos imemoriais erigidos em torno da convicção de que a mulher seria intrinsecamente ligada à sensibilidade (lágrimas nos olhos, figura 2), à fraqueza e à dor. Discursos, portanto, que subjetivavam a mulher como resultado do seu sistema reprodutivo, fundamento de sua vida social e de seus comportamentos. Útero e ovários figuram como índices de determinação da sua conduta, na medida em que esses órgãos seriam os responsáveis pelos incômodos e pela melancolia, e isso, certamente, aponta para a posição de mulher reduzida à sua capacidade reprodutora e às limitações da menstruação e da gravidez. Incapazes, aos olhos da medicina da época, de raciocínios longos, abstrações e atividade intelectual, sua constituição física, aliada à sensibilidade emocional, transformava as mulheres em sujeitos aptos apenas para a procriação e a criação dos filhos.

Toda a (des)valorização do útero aponta, igualmente, para a posição da mulher histérica. O que permite tal associação é o fato de que, durante o século XVIII, a sensibilidade e a debilidade ditas femininas foram denominadas pelos médicos da época como "afecção vaporosa", ou simplesmente "vapores", mas a vulgarização do termo transformou-o em "histeria" (CASA NOVA, 1996). No final do século XIX, a histeria ainda era vista como uma doença associada à fragilidade e às carências exclusivamente femininas. A etimologia esclarece essa crença, pois sua origem vem da palavra grega hystera, que significa justamente útero. Acreditava-se que era dele que migrava o sangue contaminado e, ao atingir o cérebro, provocava as convulsões. Muitas mulheres diagnosticadas como histéricas foram encerradas nos mesmos asilos e manicômios que os epilépticos e os doentes mentais.

Os processos de histerização e a consequente necessidade de uma medicalização minuciosa do corpo feminino assumem especial relevância na construção discursiva da identidade do feminino e os efeitos desses processos são bastante disseminados em textos de diferentes gêneros. Considerando que o enunciado não existe isolado, uma vez que sempre estabelece correlações com outros enunciados a que pode estar ligado (FOUCAULT, 2007), os romances da 
literatura do século XIX e início do século XX fornecem reincidentes histórias de mulheres histéricas cujos desequilíbrios estariam associados à ausência de uma vida sexual, até porque se acreditava que a insatisfação do prazer e do desejo seria a fonte de melancolia, desânimo (figura 1), tristeza, sofrimento, suplício (figura 2). São sintomas que, quando não tratados, poderiam provocar anormalidades mentais.

Ainda sobre a questão da histeria, volto a Foucault (1988, p.115) para sublinhar que:

[...] o tríplice processo pelo qual o corpo da mulher foi analisado qualificado e desqualificado - como corpo integralmente saturado de sexualidade; pelo qual, este corpo foi integrado, sob o efeito de uma patologia que lhe seria intrínseca, ao campo das práticas médicas; pelo qual, enfim, foi posto em comunicação orgânica com o corpo social (cuja fecundidade regulada deve assegurar), com o espaço familiar (do qual deve ser elemento substancial e funcional) e com a vida das crianças (que produz e deve garantir), através de uma responsabilidade biológico-moral que dura todo o período da educação: a Mãe, com sua imagem em negativo que é a "mulher nervosa", constitui a forma mais visível desta histerização.

Há ainda mais um ponto a ser observado. Todo esse exercício de retorno ao arquivo, às condições históricas dos discursos que definiram marcas corporais da mulher (e do homem, obviamente), levou-nos ao encontro das verdades que tentaram decifrar o caráter enigmático da sexualidade feminina. Não há dúvidas de que o centro mais forte de formação das práticas de controle da história das mulheres se concentra no mistério do ciclo menstrual e na "estranha" capacidade de a mulher gerar a vida humana. As inquietações de nossos antepassados geraram as axiologias já discutidas; mas geraram também outras e estas, por sua vez, geraram interditos e criaram lendas, mitos, crenças, preconceitos, tabus sobre a menstruação.

Observemos que as formulações linguístico-discursivas das peças falam do corpo feminino e de suas especificidades sem, contudo, usar a palavra "menstruação". Para referi-la, enunciam: incômodos, moléstia das senhoras. A interdição do uso dessa palavra no espaço publicitário atravessa o tempo e chega aos dias de hoje ainda alimentando os mesmos tabus e preconceitos.

Novamente é na esteira de Foucault (1988) que busco entender o porquê de tal silenciamento, mais detidamente quando ele, ao tratar da "explosão discursiva a propósito do sexo" e do fato de que nem tudo pode ser dito, salienta:

Talvez tenha havido uma depuração - e bastante rigorosa - do vocabulário autorizado. Pode ser que se tenha codificado toda uma retórica da alusão e da metáfora. Novas regras de decência, sem dúvida 
alguma, filtraram as palavras: definiu-se de maneira muito mais estrita onde e quando não era possível falar dele; em que situações, entre quais locutores, e em que relações sociais; estabeleceram-se, assim, regiões, senão silêncio absoluto, pelo menos de tato e discrição: entre pais e filhos, por exemplo, ou educadores e alunos, patrões e serviçais. É quase certo ter havido aí toda uma economia restritiva. Ela se integra nessa política da língua e da palavra [...]. (FOUCAULT, 1988, p. 22-23).

Não designar a menstruação, assim como não designar uma série de outros fenômenos atrelados à sexualidade, segue esses mecanismos que instauraram regras, filtraram palavras e transformaram-na, especificamente a menstruação, em um discurso indecente e proibido. Basta notar que as publicidades atuais mobilizam constantemente metáforas quando trata desse tema, ou fazem alusões sem jamais colocar a palavra "proibida" em discurso. Em anúncios televisivos de absorventes, por exemplo, na tentativa de comprovar a capacidade de absorção do produto, além de não enunciarem a palavra em questão, substituem o líquido vermelho, análogo ao sangue menstrual, por um líquido azul translúcido que não causa nenhum estranhamento por se associar, ao que parece, a algo mais puro, mais limpo (sangue real?). O azul é mostrável, dizível; o vermelho, interdito. Mas por que não se pôde, ontem, e se evita hoje denominar o sangramento feminino na prática publicitária?

Acreditava-se, há não muito tempo, que uma mulher menstruada deveria ficar isolada, evitar contato sexual, não cozinhar ou mesmo tocar nos alimentos. Alguns diziam que havia excesso de sangue no corpo da mulher; outros defendiam que o sangramento mensal escorria para purificar (renovar) o sangue da mulher. Poderia repassar muitas outras tradições, certezas e suposições sobre a questão da menstrução, mas o que importa é que, ainda hoje, muitas dessas verdades permanecem cristalizadas no imaginário social, promovendo um sem-número de práticas divisoras que atrelam ao corpo da mulher os males e as moléstias que a história construiu.

São crenças que surgiram fundamentalmente a partir da tentativa, como já foi dito, de interpretar o corpo e, em decorrência, os fenômenos relativos ao processo reprodutivo feminino. As conclusões a que se chegaram nos primórdios associavam o sangue das mulheres a um sangue impuro, sangue que, ao escorrer involuntariamente era tido como "perda" e "sinal de morte", diferentemente do sangue macho dos guerreiros que irrigava a terra de glória, virtude, energia, bravura e coragem. Daí o silêncio do pudor, ou mesmo a vergonha e o encerramento da menstruação no espaço mais privativo possível: " [...] ver correr seu sangue ou não vê-lo mais é essencial para as mulheres, mas na intimidade do corpo, no segredo do sexo, e quase sempre no maior desconforto." (PERROT, 2007, p. 45). Somente recentemente, por volta dos anos 1970, é que se começa a falar de menstruação no âmbito familiar e a publicidade integra esse diálogo apresentando as melhores 
e mais discretas proteções para as mulheres se protegerem do incômodo e do constrangimento daqueles dias.

\section{Considerações finais}

Nas publicidades antigas apresentadas e analisadas, além de muitas outras, os enunciados reatualizam outros enunciados advindos do interdiscurso no qual se sobressai o discurso médico. Eles se entrecruzam para dar a medida daquilo que se entendia ser o corpo feminino, partindo-se, muitas vezes, da ideia de que as mulheres deveriam conter seus anseios amorais e, para isso, tal como explicou Foucault, precisavam ser reguladas, educadas e enquadradas nos limites do seu corpo. O mundo feminino era o mundo do orgânico e, para descrevê-lo, devia-se falar a linguagem da medicina, conforme observa Perrot (2005), e, para controlá-lo, devia-se falar a linguagem do médico.

Não ignoramos o fato de que as mulheres ocuparam, ao longo de sua história, outros espaços além dos descritos neste estudo, ou seja, nem sempre ela foi subjetivada como doente ou inferior; nem sempre os homens controlaram os poderes e elaboraram os saberes sobre o ser feminino. Entretanto, as imagens publicitárias analisadas indicaram apenas a relação de poder que produziu a sujeição do corpo subordinado e fraco da mulher, reproduzindo a ordem social que contribuiu para a instauração de uma biopolítica das relações entre os sexos, ou melhor, para uma "sexualização" do gênero.

Os discursos de resistência, as tensões e as negociações que propiciaram cada vez mais a emergência de identidades femininas autônomas, complexas e plurais foram muito timidamente se inscrevendo nos discursos publicitários, sobretudo a partir dos anos 60. As questões feministas, a partir de então, começaram a ganhar visibilidade e dizibilidade nas práticas cotidianas de tal modo que o funcionamento discursivo dos anúncios aqui apresentados parece esquecido, apagado, absorvido na memória, como se não tivesse ocorrido. Sem a pretensão de despertar os textos de seu sono, como alertou Foucault (2007), recuamos ao que já foi dito na mídia sobre os corpos femininos para examinar as redes de formulações, o tecido constituído pelos discursos já-ditos que possibilitam analisar os efeitos da memória, isto é, as reformulações, repetições, rupturas, negações, etc., na constituição da identidade do feminino na contemporaneidade.

WITZEL, D. G. Discourse, history and female figure in old advertisements. Alfa, São Paulo, v.58, n.3, p.525-539, 2014.

- ABSTRACT: Located in the frontiers the Discourse Analysis established from the aspect proposed by Michel Foucault, the present study aims to show how the advertising discourse, which circulated in the first half of the 20th century in Brazil, contributed to the development 
of a biopolitics of the relations among genders, more precisely to the "sexualization" of the genre. The Foucauldian idea that the biopower is what can be inflicted either to a body intended to discipline or a population that is sought to regulate is the basis, upon examining the discourse function of advertising pieces when directed to women, we are led to other discourses intertwined in the memory, to the interdiscourse, defining women into their fragile bodies and their motherly function, according to the knowledge, power and truth which traditionally regulate the ideals of femininity and allowed the emergence of certain words (and not others).

- KEYWORDS: Discourse. Advertisement. Female figure. Power-knowledge.

\section{REFERÊNCIAS}

BAYER. Reclames da Bayer (1911-1942). São Paulo: Bayer do Brasil, 1986.

CASA NOVA, V. Lições de almanaque: um estudo semiótico. Belo Horizonte: Ed. da UFMG, 1996.

FOUCAULT, M. Arqueologia do saber. Rio de Janeiro: Forense Universitária, 2007.

História da sexualidade. Rio de Janeiro: Edições Graal, 1988. (A vontade de saber; v.1).

Microfísica do poder. Rio de Janeiro: Graal, 1979.

GREGOLIN, M. R. Análise do discurso e mídia: a (re)produção de identidades. Comunicação, Mídia e Consumo, São Paulo, v. 4, n. 11, p. 11-25, nov. 2007.

MACHADO, R. Foucault, a ciência e o saber. Rio de Janeiro: Jorge Zahar, 2006.

Por uma genealogia do poder. In: FOUCAULT, M. Microfísica do poder. Rio de Janeiro: Graal, 1979. p. VII-XXIII.

MATOS, M. I. S.; SOIHET, R. O corpo feminino em debate. São Paulo: Ed. da UNESP, 2003.

PERROT, M. Minha história das mulheres. São Paulo: Contexto, 2007.

As mulheres ou os silêncios da história. Bauru: EDUSC, 2005.

Os silêncios do corpo da mulher. In: MATOS, M. I. S.; SOIHET, R. O corpo feminino em debate. São Paulo: Ed. da UNESP, 2003. p. 13-27.

PORTER, R. História do corpo. In: BURKE, P. (Org.). A escrita da história: perspectivas. São Paulo: Ed. da UNESP, 1992. p. 291-326.

REVEL, J. Foucault: conceitos essenciais. São Carlos: Claraluz, 2005.

Recebido em outubro de 2013.

Aprovado em novembro de 2013. 
